\title{
Prevalence of Depression and Anxiety in Rural Health Centre Chitral, Pakistan: A Cross Sectional Study
}

\section{Sidra Kanwal ${ }^{1 *}$, Nisar Hussain ${ }^{2}$ and Waris Qidwai ${ }^{3}$}

${ }^{1}$ Specialist Family Medicine, Primary Health Care, Qatar

${ }^{2}$ Consultant Family Physician, Aga Khan Health Centre Booni Chitral, Pakistan

${ }^{3}$ Professor and Chair of Department of Family Medicine, Aga Khan Univerity

Hospital, Karachi, Pakistan

*Corresponding Author: Sidra Kanwal, Specialist Family Medicine, Primary

Health Care, Qatar. skanwal1986@yahoo.com

DOI: $10.31080 /$ ASMS.2020.04.0710
Received: July 21, 2020

Published: August 18, 2020

(C) All rights are reserved by Sidra Kanwal., et al.

\section{Abstract}

Introduction: Globally depression is a leading cause of disability and contributes to one third of global burden of diseases. More than 150 million adults suffer from depression at any point in time and nearly one million commit suicides every year. Despite immense diversity in the socio-cultural environments in Pakistan, there is an overall very high prevalence of anxiety and depression in rural Pakistan.

Patients and Methodology: All patients from March to August 2015 presented to family medicine clinics in rural health area Booni Centre Chitral for general medical problems fulfilling the inclusion criteria recruited via convenience sampling. Data then entered in SPSS 21. Patient health questionnaire (PHQ 9) and generalized anxiety disorder (GAD) 7 questionnaires were administered for assessment of depression and anxiety respectively. Sociodemographic factors were also assessed.

Results: In a sample size of 230 patients $71 \%$ of participants were of range of 18 - 35 years. Mean age was 31.3 years. Male were 118 (51.3\%) were found to be in higher proportion as compare to females.

Prevalence of depression of found to be $67 \%$, and GAD was found to be $33.5 \%$, living alone and female gender were found to be associated with Depression and anxiety with p-value $=<0.005$ and p-value $=0.025$ respectively.

Conclusion: As there is a high rate of depression in Chitral, education and support from family, friends is a strong factor in dealing with depression. Launch of a mental health program in Chitral specifically addressing gender and different age groups will be a big step towards successful rehabilitation of individuals.

Keywords: Depression; Anxiety; Chitral

\section{Introduction}

Worldwide, depression is the leading cause of disability and contributes about one third of global burden of disease [1]. There is more than 300 million people around the world suffering from depression and quarter of them are with anxiety as well. Globally in USA it is found that prevalence major depression is $6.7 \%$ and anxiety is $18 \%$ [2] a survey of 6,000 individuals in China adults estimates the prevalence of depression is $12.12 \%$ [3] and also emphasizes the significance of healthy relationship with family to improve overall mental health status. In terms of sociodemographic variables a study in India shows that depression is more prevalent in women those residing in nuclear family [4] and prevalence rate was $15.1 \%$ [5] a study conducted in Pakistan showed prevalence of 
depression in three capital cities were in between $35.7 \%-53.4 \%$ [1]. Pakistan has 180 million people and is the $9^{\text {th }}$ most populous country in the world [6] here overall prevalence of anxiety and depression is $33.6 \%$ [2]. The contributing factors linked with these two illnesses included increasing age, lesser education, abuse, and violence, being a housewife, relationship problems, being single, having more than four children and housing problems.

There is an estimate of only 1 psychiatrist for every 10000 individuals [7].

Depression significantly impose huge economic burden in the society [8]. Furthermore, it affects functionality of the person and may lead to substance abuse and eventually suicide and death, hence this need to address on priority basis.

According to a study in Gilgit [9] 50\% ( $n=60)$ of total women in the study population suffered from psychiatric disorders, $25 \%$ (n $=30)$ of them had anxiety neurosis, $17 \%(n=20)$ had anxiety and depression, $8 \%(n=10)$ were found to be depressed.

In rural areas of Pakistan, especially in northern areas of chitral, communities usually endure with natural frequent disaster, poverty, unemployment, and lack of city amenities. Medical facilities are very limited here. Earlier study in Chitral showed that $46 \%$ of women suffered from anxiety and depression [10] our study conducted in a rural secondary care health centre situated in Booni Chitral, which has community of 20 thousand local residents. We intended to conduct a cross- sectional survey and intended to find out the frequency of depression and anxiety and sociodemographic factors contributing to depression and anxiety in patients presenting to rural health center Booni, Chitral. This will allow in future to plan targeted prevention strategies.

\section{Methodology}

A cross-sectional study was conducted in 230 patients presenting in family medicine clinics. Those patient who fulfill the inclusion criteria from March to August 2015 presented on clinic day were included in the survey. Non-probability convenience sampling was done. The inclusion criteria were: informed consent, age 18 years and above, able to understand Urdu language exclusion criteria were those who diagnosed to have depression and anxiety by any physician or recent hospitalization within last 6 weeks.
Primary investigator administered questionnaire in Urdu by herself to the patients who were attending in outpatient family medicine clinics for the first time with different general medical complaints. Interview conducted in standard conditions in separate room and with single patient at one time. Questionnaire includes three parts, first part include Sociodemographic factors, second include PHQ 9 and third part include GAD 7 scale.

Demographic information form was administered to collect participants' demographic information like age, gender, living status, education level, occupation, comorbids, socioeconomic status etc.

Patient health questionnaire (PHQ 9) which is a validated screening tool and has been used in many studies [11,12]. PHQ-9 has $61 \%$ sensitivity and $94 \%$ specificity in adults. The PHQ-9 is the depression module, which scores each of the 9 DSM- IV criteria as "0" (not at all) to "3" (nearly every day). Depression Severity assed as 0 - 4 none, 5 - 9 mild, 10 - 14 moderate, and > 15 severe depression.

Generalized anxiety disorder GAD 7 questionnaire were administered [13]. It is a seven-item; self-report anxiety questionnaire designed to assess the patient's health status during the previous 2 week. The GAD-7 has a sensitivity of $89 \%$ and a specificity of $82 \%$ for GAD.

Data was double entered i.e. entered and cross checked by independent researcher using SPSS 19 software, and data analysis was also done by same software.

Baseline information on demographics analyzed using descriptive statistics. For categorical variables such as gender, age, education, working status, living status, socieconomic status frequencies and proportions reported. To identify the relation of demographic variables (gender, educational status, living status) with outcome variables CHISQUARE test and cross tab stratification had applied. Mean + SD has calculated for age. $p$-value $<0.005$ considered to be significant.

\section{Results}

In a sample size of 230 patients $71 \%(n=164)$ of participants were of range of 18- 35 years. Mean age was found to be 31.3 years.

Male were 118 (51.3\%) were found to be in higher in number, female proportion was $48.7 \%(n=112)$. 
The number of respondents who had no formal education were $20 \%,(n=46)$.

Most of respondents belong to middle class family $46.5 \%$, (n $=107)$. Moreover, the number of individuals who were employed were $47.9 \%(n=108)$, most of them, retailer salesperson.

Disease co morbidity like diabetes and hypertension prevalence found to be $31.3 \%(n=72)$ detailed demographics are in table 1.

\begin{tabular}{|c|c|c|}
\hline \multicolumn{3}{|c|}{ Sociodemographic Variables } \\
\hline Variable & $\begin{array}{c}\text { Number/ } \\
\text { Frequency }\end{array}$ & Percentage \\
\hline \multicolumn{3}{|l|}{ Age } \\
\hline 18-25years & 83 & $36 \%$ \\
\hline $26-35$ years & 81 & $35 \%$ \\
\hline $36-60$ years & 58 & $25 \%$ \\
\hline 60-80years & 8 & $3.4 \%$ \\
\hline \multicolumn{3}{|l|}{ Gender } \\
\hline Male & 118 & $51.3 \%$ \\
\hline Female & 112 & $48.7 \%$ \\
\hline \multicolumn{3}{|l|}{ Education } \\
\hline Illiterate & 46 & $20.0 \%$ \\
\hline Primary education & 36 & $15.7 \%$ \\
\hline Secondary education & 34 & $14.8 \%$ \\
\hline Intermediate & 14 & $6.1 \%$ \\
\hline Higher education & 100 & $43.5 \%$ \\
\hline \multicolumn{3}{|l|}{ Living status } \\
\hline Living alone & 52 & $22.5 \%$ \\
\hline Living with company & 178 & $77.4 \%$ \\
\hline \multicolumn{3}{|l|}{ Socioeconomic status } \\
\hline Low & 68 & $29.6 \%$ \\
\hline Middle & 107 & $46.5 \%$ \\
\hline Higher & 55 & $23.9 \%$ \\
\hline \multicolumn{3}{|c|}{ Number of Family Members } \\
\hline $2-4$ & 15 & $6.5 \%$ \\
\hline $4-6$ & 51 & $22.2 \%$ \\
\hline $6-8$ & 41 & $17.8 \%$ \\
\hline 8-10 & 53 & $23.0 \%$ \\
\hline$>10$ & 70 & $30.4 \%$ \\
\hline \multicolumn{3}{|l|}{ Comorbids } \\
\hline Yes & 72 & $31.3 \%$ \\
\hline No & 157 & $68.3 \%$ \\
\hline \multicolumn{3}{|l|}{ Working status } \\
\hline Yes & 108 & $47.9 \%$ \\
\hline No & 120 & $51.3 \%$ \\
\hline
\end{tabular}

Table 1
It is also found that those who live with someone have less depression and anxiety, odds ratio 0.088 and 0.189 respectively with $\mathrm{p}$ value $=<0.05$ (Table 2). Moreover statistical analysis showed that females are 2.4 times more prone to develop anxiety but depression ratio was similar in both genders (Table 3) furthermore it could be stated that severe depression could be found in female population (Table 4).

Prevalence of depression of found to be $67 \%$, with break up shown in figure 1-4 \% = 19 individuals were found to have severe depression and GAD was found to be $33.5 \%$, living alone and female gender were found to be associated with Depression and anxiety with $\mathrm{p}$ value of 0.001 .

\section{Discussion}

Previously it was believed that mental health of people living in rural area far away from modern fast growing world is much better than people live in urban set up because; in remote part of world they led a stress free life [14], but our study show vice versa results. In Pakistan overall prevalence of anxiety and depressive disorders in the community population was $34 \%$ [2], but this study observe that the ratio is double in rural area Chitral Pakistan.

Depression and anxiety disorder are two most important mental health disorder seen in general population. Our study had population had mean age of 31 years +10.8 year, that is comparable to other studies in Pakistan i.e. mean age of 30 years \pm 8.9 years [15].

This study confirmed the finding of earlier studies which stated that there is strong association of depression and female gender $[10,16]$. This may be because of insufficient learning opportunities for females, generally they were housewives.

Furthermore early marriages early motherhood and adjustment issues are customary, as most of the time spouse live in urban setup for their jobs. This is constant with previous studies [15].

An interesting observation in this study illustrate that living alone is a risk factor for depression. Although Joint family is a protective factor for prevention of depression [17]. Most of population in chitral live in joint family system about 8-10 family members live in a house but there is no such association of number of family members and prevalence of depression and anxiety can be found in our study. 


\begin{tabular}{|c|c|c|c|c|c|c|c|}
\hline Depression & $\begin{array}{l}\text { Living } \\
\text { alone }\end{array}$ & $\begin{array}{c}\text { Living } \\
\text { with } \\
\text { company }\end{array}$ & \multirow[t]{3}{*}{$\begin{array}{c}\text { p- value } \\
0.000\end{array}$} & $\begin{array}{c}\text { Generalized } \\
\text { Anxiety } \\
\text { disorder }\end{array}$ & $\begin{array}{l}\text { Living } \\
\text { alone }\end{array}$ & $\begin{array}{c}\text { Living } \\
\text { with } \\
\text { company }\end{array}$ & \multirow[t]{3}{*}{$\begin{array}{c}\text { P-value } \\
0.000\end{array}$} \\
\hline Yes & 49 & 105 & & Yes & 33 & 44 & \\
\hline No & 3 & 73 & & No & 19 & 134 & \\
\hline
\end{tabular}

Table 2: Living status.

\begin{tabular}{|l|l|l|l|l|l|l|l|}
\hline Depression & Male & Female & P-value & GAD & Male & Female & \multirow{2}{*}{ p-value 0.02 } \\
Odd ratio 2.4
\end{tabular}

Table 3: Gender.

\begin{tabular}{|l|c|c|c|c|c|c|}
\hline \multirow{2}{*}{ Gender } & No depression & Mild depression & \multirow{2}{*}{$\begin{array}{c}\text { Moderate } \\
\text { depression }\end{array}$} & $\begin{array}{c}\text { Severe } \\
\text { depression }\end{array}$ & \multicolumn{2}{|c|}{ Generalized Anxiety disorder } \\
\cline { 5 - 8 } & & & 23 & 6 & 29 & Yo \\
\hline Male & 39 & 50 & 22 & 13 & 48 & 64 \\
\hline
\end{tabular}

Table 4: Severity of depression.

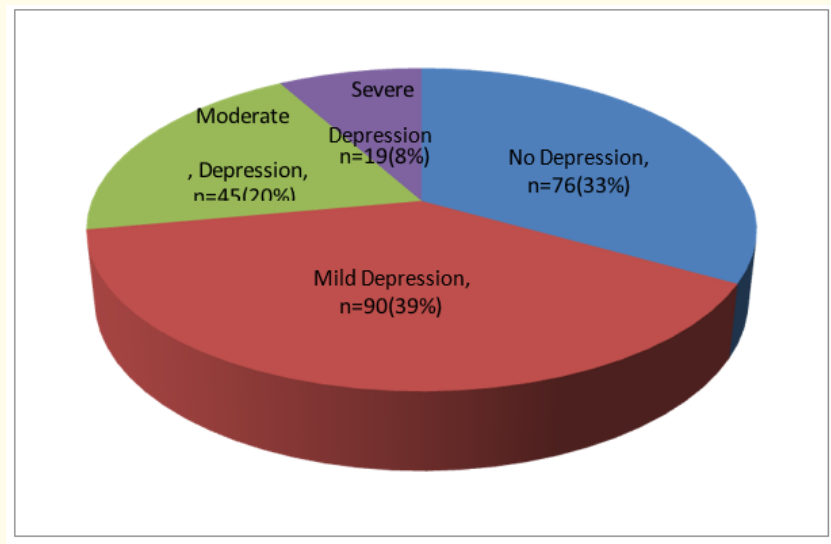

Figure 1: Prevalence of depression in chitral according to severity of depression.

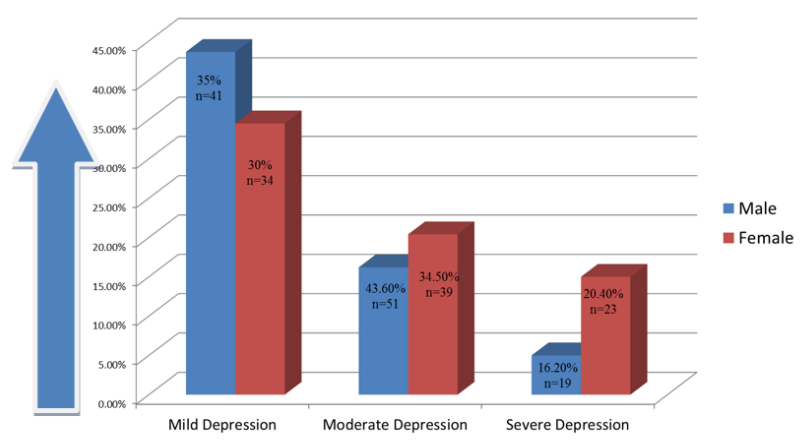

Figure 2: Sociodemographic factor: Gender and depression. 


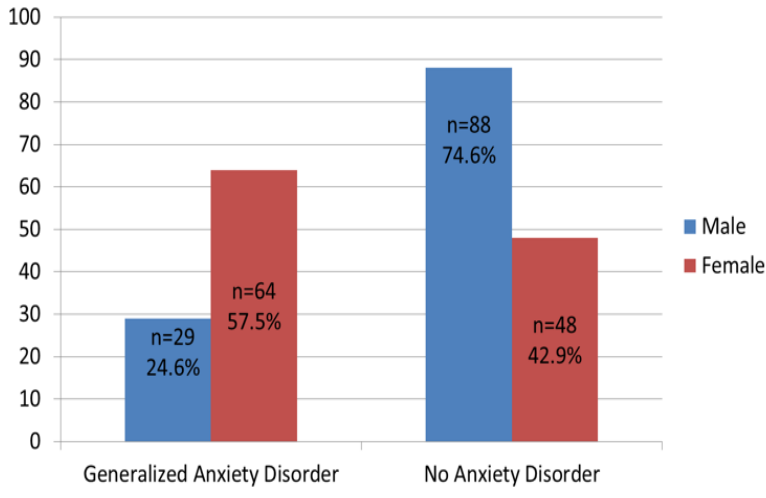

Figure 3: Sociodemographic factor: Gender and anxiety.

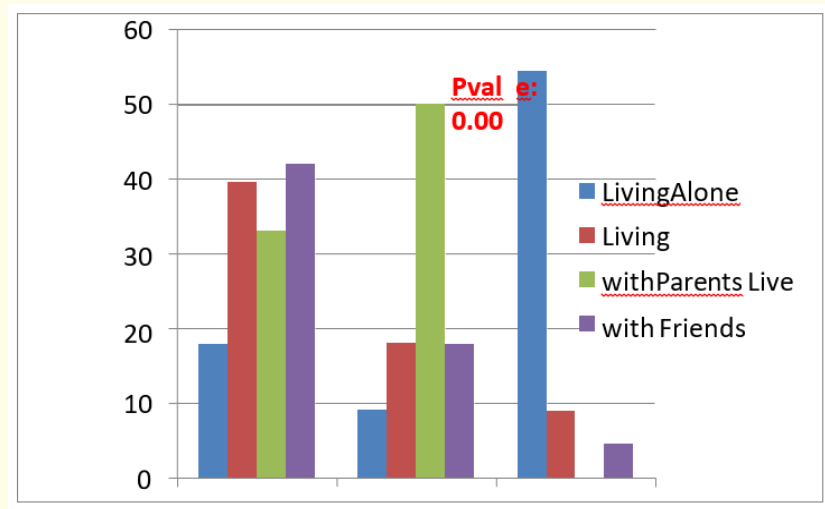

Figure 4: Sociodemographic factor: living status and depression.

Our estimated prevalence of depression was found to be $67 \%$ this is still higher as compare to other rural areas in Sindh in which the prevalence is $43 \%$ [17] this may be due to difference in social circumstances and one factor can be the cold weather in chitral as well.

Moreover, there was no association of co morbidities and depression and anxiety in contrast to other studies [18] this could be due to perception for disease is low in local population.
Unlike previous studies [19] relation could not identify between socioeconomic status and depression and anxiety this could be because in chitral most of people earned by farming and running small local small business selling goats. Generally, they owe their individual houses. They don't have obligation to pay huge so the everyday expenditure are very near to the ground.

\section{Limitations of the Study}

Inherent problem of study designs that its a cross sectional survey is there so we could not established the temporality between the anxiety and depression and other associated factors, however we feel similar research needs to be conducted in prospective cohort design in a larger sample size It has conducted in Chitral Booni Area which is obviously not the representative of all the population of area

\section{Conclusion}

- Prevalence of Depression and Anxiety in Chitral rural area is almost double as compared to National data.

- Strengthening primary care, launch of a mental health program and training the physicians of Chitral to treat common mental health problems will help to reduce the disease burden.

\section{Acknowledgment}

We wish to thanks Aga Khan Health services Booni chitral staff who gave us the opportunity to conduct the study and facilitate us and also to the patients of the centre the without whose help this study would not have been possible.

We also want to acknowledge statistical support from Ms Kashmira Nanji who is a senior instructor and Bio-statistician in Aga khan Family medicine department.

\section{Contribution of Authors}

- Dr Sidra Kanwal did the data collection, data entry, analysis, compiled the results and prepared the first draft.

- Dr Nisar Hussain helped in data collection and making questionnaire, gave his intellectual advise on manuscript write up.

- Dr Waris Qidwai was behind the conception and design of the study, did the final revisions critical and supervised all the above authors. 


\section{Bibliography}

1. Gadit AAM and Mugford G. "Prevalence of depression among households in three capital cities of Pakistan: need to revise the mental health policy". Plos One 2.2 (2007): e209.

2. Mirza I and Jenkins R. "Risk factors, prevalence, and treatment of anxiety and depressive disorders in Pakistan: systematic review". BMJ 328.7443 (2004): 794.

3. Qin X., et al. "The prevalence of depression and depressive symptoms among adults in China: Estimation based on a National Household Survey". China Economic Review 51 (2016): 271-282.

4. Jain R and Aras R. "Depression in geriatric population in urban slums of Mumbai". Indian Journal of Public Health 51.2 (2007).

5. Poongothai S., et al. "Prevalence of depression in a large urban South Indian population-The Chennai Urban Rural Epidemiology study (CURES-70)”. PLoS One 4.9 (2009): e7185.

6. Bhamani MA., et al. "Depression in the elderly in Karachi, Pakistan: a cross sectional study". BMC Psychiatry 13.1 (2013): 181.

7. Altaf A., et al. "Sociodemographic Pattern of Depression in Urban Settlement of Karachi, Pakistan". Journal of Clinical and Diagnostic Research: JCDR 9.6 (2015): VC09.

8. Greenberg PE and Birnbaum HG. "The economic burden of depression in the US: societal and patient perspectives". Expert Opinion on Pharmacotherapy 6.3 (2005): 369-376.

9. Dodani S and Zuberi RW. "Center-based prevalence of anxiety and depression in women of the northern areas of Pakistan". Journal of Pakistan Medical Association 50.5 (2000): 138.

10. Mumford DB., et al. "Stress and psychiatric disorder in the Hindu Kush: a community survey of mountain villages in Chitral, Pakistan". The British Journal of Psychiatry 168 (1996): 299-307.

11. Arrieta J., et al. "Validity and Utility of the Patient Health Questionnaire (PHQ)-2 and PHQ-9 for Screening and Diagnosis of Depression in Rural Chiapas, Mexico: A Cross-Sectional Study". Journal of Clinical Psychology 73.9 (2017): 1076-1090.
12. Gholizadeh L., et al. "Sensitivity and specificity of Urdu version of the PHQ-9 to screen depression in patients with coronary artery disease". Contemporary Nurse 53.1 (2017): 75-81.

13. Sawaya H., et al. "Adaptation and initial validation of the Patient Health Questionnaire - 9 (PHQ-9) and the Generalized Anxiety Disorder - 7 Questionnaire (GAD-7) in an Arabic speaking Lebanese psychiatric outpatient sample". Psychiatry Research 239 (2016): 245-252.

14. Parry-Jones WL., et al. "Mental health and deviance in inner cities" (1991).

15. Naeem S. "Prevalence of and factors associated with anxiety and depression among women in a lower middle class semiurban community of Karachi, Pakistan". Studies 20 (2002): 23.

16. Husain N., et al. "Life stress and depression in a tribal area of Pakistan". The British Journal of Psychiatry 190.1 (2007): 3641.

17. Barrett AE and Turner RJ. "Family structure and mental health: The mediating effects of socioeconomic status, family process, and social stress". Journal of Health and Social Behavior 46.2 (2005): 156-169.

18. Luni FK., et al. "Prevalence of depression and anxiety in a village in Sindh". Journal of Ayub Medical College, Abbottabad: JAMC 21.2 (2009): 68-72.

19. Freeman A., et al. "The role of socio-economic status in depression: results from the COURAGE (aging survey in Europe)". BMC Public Health 16.1 (2016): 1098.

\section{Assets from publication with us}

- Prompt Acknowledgement after receiving the article

- Thorough Double blinded peer review

- Rapid Publication

- Issue of Publication Certificate

- High visibility of your Published work

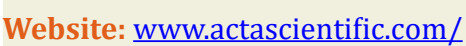

Submit Article: www.actascientific.com/submission.php

Email us: editor@actascientific.com

Contact us: +919182824667 